Research Paper

\title{
Effect of Metoprolol Succinate in Patients with Stable Angina and Elevated Heart Rate Receiving Low-Dose $\beta$-Blocker Therapy
}

Jie Jiang, ${ }^{1}$ Hongliang Cong, ${ }^{2}$ Yan Zhang, 1 Zhanquan Li, ${ }^{3}$ Guizhou Tao, ${ }^{4}$ Xiaodong Li, ${ }^{5}$ Liang Qing, 6 Ning Tan, ${ }^{7}$ Zhichen Zhao, ${ }^{8}$ Yugang Dong, ${ }^{9}$ Zheng Ji, ${ }^{10}$ Yundai Chen, ${ }^{11}$ Junbo Ge, ${ }^{12}$ Ben He, ${ }^{13}$ Yingxian Sun, ${ }^{14}$ Kejiang Cao, ${ }^{15}$ Yong Huo ${ }^{1 凶}$

1. Peking University First Hospital, 8 Xishiku Street., Xicheng District, Beijing, 100034;

2. Tianjin Chest Hospital, 93 Xian Road, Heping District, Tianjin, 30051;

3. The People's Hospital of Liaoning Province, 33 Wenyi Road, Shenhe District, Shenyang, Liaoning, 110016;

4. The First Affiliated Hospital of Liaoning Medical University, 2 Renmin Street, Jinzhou, Liaoning, 121004;

5. Shenging Hospital of China Medical University, 36 Sanhao street, Heping District, Shenyang, Liaoning, 110004;

6. Taiyuan Chaoyang Hospital, 7 Youdianqian Street, Yingze District, Taiyuan, Shanxi, 030001

7. Guangdong General Hospital, 106 Zhongshan 2nd Road, Guangzhou, Guangdong, 510080;

8. Zhengzhou Central Hospital, 195 Tongbai Road, Zhongyuan District, Zhengzhou, Henan, 450007;

9. The First Affiliated Hospital, Sun Yat-sen University, 58 Zhongshan 2nd Road, Guanzhou, Guangdong, 510080;

10. Tangshan Gongren Hospital, 27 Wenhua Road, Lubei District, Tangshan, Hebei, 63000;

11. Chinese PLA General Hospital, 28 Fuxing Road, Haidian District, Beijing, 100039;

12. Zhongshan Hospital Fudan University, 180 Fenglin Road, Xuhui District,Shanghai, 200032;

13. Renji Hospital Shanghai Jiaotong University School of Medicine, 786 Yuyuan Road, Changning District, Shanghai, 200240;

14. The First Hospital of China Medical University, 155 Nanjing North Street, Shenyang, Liaoning, 110001;

15. Jiangsu Province Hospital, 300 Guangzhou Road, Gulou District, Nanjing, Jiangsu, 210029.

$\triangle$ Corresponding author: Yong Huo, Address: Peking University First Hospital, 8 Xishiku St, Xicheng District, Beijing 100034, China Fax: 86-10-66551383; Telephone: 86-10-83572283; Email: huoyong@263.net.cn

(C) Ivyspring International Publisher. This is an open access article distributed under the terms of the Creative Commons Attribution (CC BY-NC) license (https://creativecommons.org/licenses/by-nc/4.0/). See http://ivyspring.com/terms for full terms and conditions.

Received: 2016.10.24; Accepted: 2017.02.26; Published: 2017.04.09

\begin{abstract}
Aims: $\beta$-blockers are underused in Chinese patients with coronary heart disease. The prescribed dose is often low. The aim of this study was to investigate the effect of metoprolol succinate doses of $95 \mathrm{mg}$ and $190 \mathrm{mg}$ on heart rate (HR) control, as well as drug tolerance, in Chinese patients with stable angina, low-dose $\beta$-blocker use and unsatisfactory HR control.

Methods: This was a multicenter, randomized, open-label, parallel-group trial in 15 clinical sites. Patients with stable angina, taking low-dose $\beta$-blockers (equivalent to metoprolol succinate $23.75-47.5 \mathrm{mg} / \mathrm{day}$ ), and having a resting $\mathrm{HR}$ of $\geqslant 65 \mathrm{bpm}$ were enrolled and randomized to either the metoprolol 95-mg group or the 190-mg group. The change in 24-h average HR from baseline recorded by Holter monitoring and the percentages of patients with resting HR controlled to $\leqslant$ $60 \mathrm{bpm}$ were compared between the two groups.

Results: Two hundred thirty-one patients entered the intent-to-treat population for the main analysis. The change in 24-h average HR from baseline was $-0.62 \pm 0.66 \mathrm{bpm}$ in the $95 \mathrm{mg}$ group and $-2.99 \pm 0.62 \mathrm{bpm}$ in the $190 \mathrm{mg}$ group $(p=0.0077)$ after 8 weeks of treatment. The percentages of patients with resting $\mathrm{HR}$ controlled to $\leq 60 \mathrm{bpm}$ were $24.1 \%$ (95\% Cl: $16.35 \%, 31.93 \%$ ) and $40.0 \%$ (95\% Cl: $31.05 \%, 48.95 \%)$, respectively $(p=0.0019)$. Only 4 and 2 of the patients, respectively, discontinued the study drugs because of hypotension or bradycardia.

Conclusions: The metoprolol succinate dose of $190 \mathrm{mg}$ is superior to the $95 \mathrm{mg}$ dose in terms of $\mathrm{HR}$ control, in Chinese patients with stable angina, low-dose $\beta$-blocker use and unsatisfactory HR control. Both doses were well tolerated.
\end{abstract}

Key words: metoprolol succinate, heart rate, stable angina, dose, tolerance. 


\section{Introduction}

Elevated heart rate (HR) is an independent risk factor for all-cause death and cardiovascular events in the general population $[1,2]$ and in patients with various cardiovascular diseases, including hypertension [3] and coronary artery disease [4]. Current guidelines in China [5] and abroad [6] recommend that the objective of stable angina treatment is to reach a target resting HR of $55-60 \mathrm{bpm}$, if tolerated, or $50 \mathrm{bpm}$ for patients who have severe angina without symptoms of bradycardia.

However, HR is not optimally controlled in patients with coronary heart disease (CHD) in clinical practice. According to the Prospective Observational Longitudinal Registry of Patients with Stable Coronary Artery Disease, $44.0 \%$ of the total 33,438 CHD patients and $41.1 \%$ of the 24,910 patients receiving various doses of $\beta$-blockers had a resting $\mathrm{HR}$ of $>70 \mathrm{bpm}$ [7]. In China, the management of HR among CHD patients is also barely satisfactory; one national survey found that the average resting HR of patients with chronic angina pectoris who were on and off $\beta$-blockers was $75 \mathrm{bpm}$ and $73 \mathrm{bpm}$, respectively [8].

$\beta$-blockers are among the most effective therapies for CHD. The clinical benefit and improvement in prognosis following $\beta$-blocker treatment in CHD patients have been associated with a reduction in resting HR [9]. In patients who have stable angina without contraindications, $\beta$-blocker therapy is recommended as a strategy to improve disease outcome and symptoms. Although $\beta$-blockers have been widely available in China for many years for the treatment of cardiovascular diseases, they are underused among CHD patients in common clinical practice. According to the Prospective Urban Rural Epidemiological study, only $6.8 \%$ of CHD patients in China had been prescribed $\beta$-blockers, which was far lower than the rate in the United States and in European countries (45.5\%) [10]. On the other hand, a national survey conducted mostly in tertiary hospitals revealed a more favorable finding, wherein $61.1 \%$ of all patients were on $\beta$-blockers [8].

Physicians' knowledge and experience in using $\beta$-blockers can have some impact on the underutilization of these drugs and, consequently, on the incidence of elevated HR. A possible reason for their lack of prescription is the concern that Chinese patients may not have the same tolerance of the higher dose of $\beta$-blockers recommended in Western countries. However, these concerns are mostly based on personal experience rather than verified evidence. Thus, a study to address the issue of $\beta$-blocker underuse and poor HR control in Chinese CHD patients is warranted.

We report herein the findings of our study involving Chinese patients with stable angina and elevated HR who were taking a low dose of $\beta$-blockers. The patients were administered different doses of metoprolol succinate (95 mg vs. $190 \mathrm{mg}$ ), and their HR as well as other safety parameters were assessed.

\section{Methods}

\section{Study design}

This multicenter, randomized, open label, parallel group study was reviewed and approved by the Ethics Committee of Peking University First Hospital. The study was performed in accordance with the principles of the Declaration of Helsinki. Patients were enrolled into the study from October 2010 to September 2011.

The study included a one-week run-in period and a randomized eight-week treatment period. During the run-in period, all subjects were treated with $47.5 \mathrm{mg}$ metoprolol succinate. The subjects were then randomized into two groups: 1) a 95-mg group receiving $47.5 \mathrm{mg}$ /day metoprolol succinate for two weeks before dose titration to $95 \mathrm{mg} /$ day; and 2) a 190-mg group receiving $95 \mathrm{mg} /$ day metoprolol succinate for two weeks before dose titration to 190 $\mathrm{mg} /$ day. Dose titrations were performed only in patients who could tolerate the first dosage without exhibiting symptoms of bradycardia-systolic blood pressure (SBP) $<100 \mathrm{mmHg}$ or $\mathrm{HR}<45 \mathrm{bpm}-$ according to a 12-lead electrocardiogram recorded after the first two weeks of randomized treatment. If a patient could not tolerate a given dose level, as confirmed by the investigator at any visit, the dose was reduced to a lower level and the patient continued to receive that dose until the end of the study, provided that the final dose was $>47.5 \mathrm{mg}$. Any patient who could not tolerate a dose of $47.5 \mathrm{mg}$ was excluded from the study After the treatment period, the drug was administered for another two weeks to ensure that the subjects were well advised concerning the type and dose of $\beta$-blocker they would have to take after the study.

\section{Patients}

The inclusion criteria of study were: 1) provision of informed consent prior to participation in the study; 2 ) Chinese patients aged $18-75$ years; 3 ) resting $\mathrm{HR} \geq 65 \mathrm{bpm} ; 4$ ) diagnosed with stable angina for at least 1 month and with stable angina pectoris symptoms within 2 weeks prior to enrollment; 5) left 
ventricular ejection fraction $(\mathrm{LVEF}) \geq 50 \%$ according to echocardiography; 6 ) on $\beta$-blockers for at least 4 weeks at a dosage equivalent to metoprolol succinate $23.75-47.5 \mathrm{mg} /$ day. This population was intended to simulate the patients we commonly encounter in clinical practice who have been prescribed a low dose of $\beta$-blockers and yet exhibit elevated HR.

The main exclusion criteria included: 1) significant clinical, laboratory, or electrocardiographic abnormalities that would place the subject at undue risk (in the Investigator's opinion), including renal impairment (serum creatinine $>2.0 \mathrm{mg} / \mathrm{dL}$ ), serum ALT or AST $>3 \times$ upper limit of reference range, serum potassium $<3.0 \mathrm{mEq} / \mathrm{L}$, serum sodium $\leq 130$ $\mathrm{mEq} / \mathrm{L}$, acute or chronic hepatitis or cirrhosis (clinical diagnosis), uncontrolled hyperthyroidism (clinical diagnosis); 2) SBP $\geq 180 \mathrm{mmHg}$, or $<100 \mathrm{mmHg}$ at enrolment; 3) PR interval > $0.24 \mathrm{~s}$ at enrollment; 4) second- or higher-degree atrioventricular block; 5) bundle branch block (complete left bundle branch block and bifascicular block or trifascicular block); 6) symptomatic bradycardia or sick sinus syndrome; 7) poorly controlled diabetes mellitus (fasting plasma glucose $>10 \mathrm{mmol} / \mathrm{L}$ or $180 \mathrm{mg} / \mathrm{dL}$ or symptomatic hypoglycemia within the past three months); 8) unstable angina or Prinzmetal's angina; 9) patients with unstable, non-compensated heart failure (pulmonary edema, hypoperfusion, or hypotension); 10) systolic heart failure with reduced LVEF; 11) severe stable symptomatic heart failure (New York Heart Association class IV); 12) cardiogenic shock; 13) hemodynamically significant disorder of cardiac valves; 14) atrial fibrillation; 15) under continuous or intermittent inotropic therapy acting through $\beta$-receptor agonism; 16) serious peripheral vascular disease with risk of gangrene; 17) asthma or chronic obstructive pulmonary disease; 18) pheochromocytoma; 19) history of allergy or intolerance to any of the components of the study drugs; 20) malignancy or life expectancy less than 6 months because of malignancy; 21) history of alcohol or drug abuse; 22) use of a medication contraindicated for use with a $\beta$-blocker agent, such as barbiturate, propafenone, or verapamil; 23) inability to be off antiarrhythmic agents (class I, III, and IV, except for dihydropyridine calcium channel blockers); 24) pregnancy or nursing an infant; 25) female of childbearing potential, unless using the following forms of birth control during this study: intra-uterine device, implantable progesterone device, progesterone intramuscular injection, oral contraceptive, or barrier method plus spermicide; 26) athlete.

\section{Outcome assessment}

The primary parameter of treatment efficacy was the 24-h average HR after eight weeks of treatment. Other parameters included: 1 ) the 24-h average HR after two weeks of treatment; 2) the change in 24-h average HR within groups after two and eight weeks of treatment; 3) the percentage of patients whose resting HR was lower than $60 \mathrm{bpm}$ after two and eight weeks of treatment; 4) the number of patients who discontinued the treatment owing to an adverse event (AE); and 5) the changes in fasting plasma glucose, total cholesterol, and triglyceride levels. Holter monitors were used to record the 24-h average HR.

\section{Statistical analysis}

To determine the difference in 24-h average HR between the two treatment groups after two and eight weeks' treatment, a mixed model of repeated measures analysis was performed on the change in 24-h average HR. This approach assumed that missing observations were missing at random, and utilized all the available data for analysis. The model included treatment, study center, baseline 24-h average HR, visit, and treatment-by-visit interaction as explanatory variables. The study center was regarded as a random effect, while all other variables were treated as fixed effects. To model the covariance structure, an unstructured covariance matrix was used. If the algorithm did not converge for the data set, a first-order autoregressive covariance structure was employed. The primary contrasts of interest were the treatment differences between the 95-mg and 190-mg groups during the eight weeks of treatment.

For comparisons of continuous variables within groups, the paired $t$-test was used. Other continuous safety parameters were analyzed using the same method as used for analyzing the change in the 24-h average $H R$.

The percentage of patients whose resting HR was controlled to $\leq 60 \mathrm{bpm}$ was analyzed in both intent-to-treat (ITT) and per-protocol populations for the two treatment groups after two and eight weeks of treatment. The comparisons were performed using a logistic regression model with factors fitted for treatment, treatment center, and baseline HR, and were presented as odds ratios (OR) with 95\% confidence intervals (CIs). For comparisons within groups, McNemar's test was used.

Categorical variables were summarized by frequency and percentage of population. The incidence and severity of AEs were analyzed for each body system and preferred term for both treatment groups. All other safety data, including physical examination, vital signs, and laboratory data, were analyzed using descriptive statistics and frequency 
distributions.

All statistical analyses were performed using SAS software (version 9.1.3; SAS Institute, Cary, NC, USA).

\section{Results}

\section{Baseline characteristics}

As shown in Figure 1, 317 patients were screened and 251 patients were randomized into one of the two treatment groups. For the 66 patients who were not enrolled into the study, the most common reasons for screening failure were voluntary discontinuation $(\mathrm{n}=$ 34 ) and incorrect enrollment $(n=27)$. Of the 251 enrolled patients, 223 patients $(88.8 \%)$ completed the treatment course while 28 patients (11.2\%) discontinued the treatment, including 12 patients $(9.6 \%)$ in the $95-\mathrm{mg}$ group and 16 patients $(12.7 \%)$ in the 190-mg group. Twenty enrolled patients had missing HR data and were thus excluded from the analysis, leaving 231 patients included in the ITT analysis (95-mg group, $\mathrm{n}=116$; 190-mg group, $\mathrm{n}=$ 115).

There were no significant differences in the baseline data between the two treatment groups (Table 1).

\section{Heart rate control}

Based on the ITT analyses, the baseline 24-h average HR was $70.9 \pm 8.19 \mathrm{bpm}$ and $71.4 \pm 8.02 \mathrm{bpm}$ for the 95-mg and 190-mg groups, respectively; after eight weeks of treatment, the 24 -h average HR was $70.9 \pm 8.71 \mathrm{bpm}$ and $68.6 \pm 8.40 \mathrm{bpm}$ for the $95-\mathrm{mg}$ and 190 -mg groups, respectively. The least square mean of the difference between the two groups was $2.36 \mathrm{bpm}$ $(95 \%$ CI: $0.63,4.09)$ after eight weeks of treatment $(\mathrm{p}=$ 0.0077; Table 2). The difference between the baseline $\mathrm{HR}$ and the HR after eight weeks was $-0.62 \mathrm{bpm}(95 \%$ CI: $-1.94,0.69)$ and -2.99 bpm (95\% CI: $-4.23,-1.75)$ in the 95-mg and 190-mg groups, respectively. There was a statistically significant change in 24-h average HR from before to after the eight-week treatment in the 190-mg group, but not in the 95-mg group.

The percentages of patients (ITT) with resting HR controlled to $\leq 60 \mathrm{bpm}$ after two weeks of treatment were $21.6 \%$ (95\% CI: $14.07 \%, 29.03 \%)$ and $24.3 \%$ (95\% CI: $16.50 \%, 32.19 \%$ ) in the $95-\mathrm{mg}$ and 190-mg groups, respectively, with the difference between the two groups being $2.8 \%$ (95\% CI: $-8.04 \%$, $13.64 \% ; p>0.05)$. Values for the same parameter after eight weeks were $24.1 \%$ (95\% CI: $16.35 \%, 31.93 \%$ ) and $40.0 \%$ (95\% CI: $31.05 \%, 48.95 \%)$ in the $95-\mathrm{mg}$ and 190-mg groups, respectively, with the difference being $15.9 \%$ (95\% CI: $4.00 \%, 27.73 \% ; p=0.0019) . \mathrm{A}$ significant increase in the percentage of patients with resting HR controlled to $\leq 60 \mathrm{bpm}$ was observed only in the 190-mg group (Table 3).

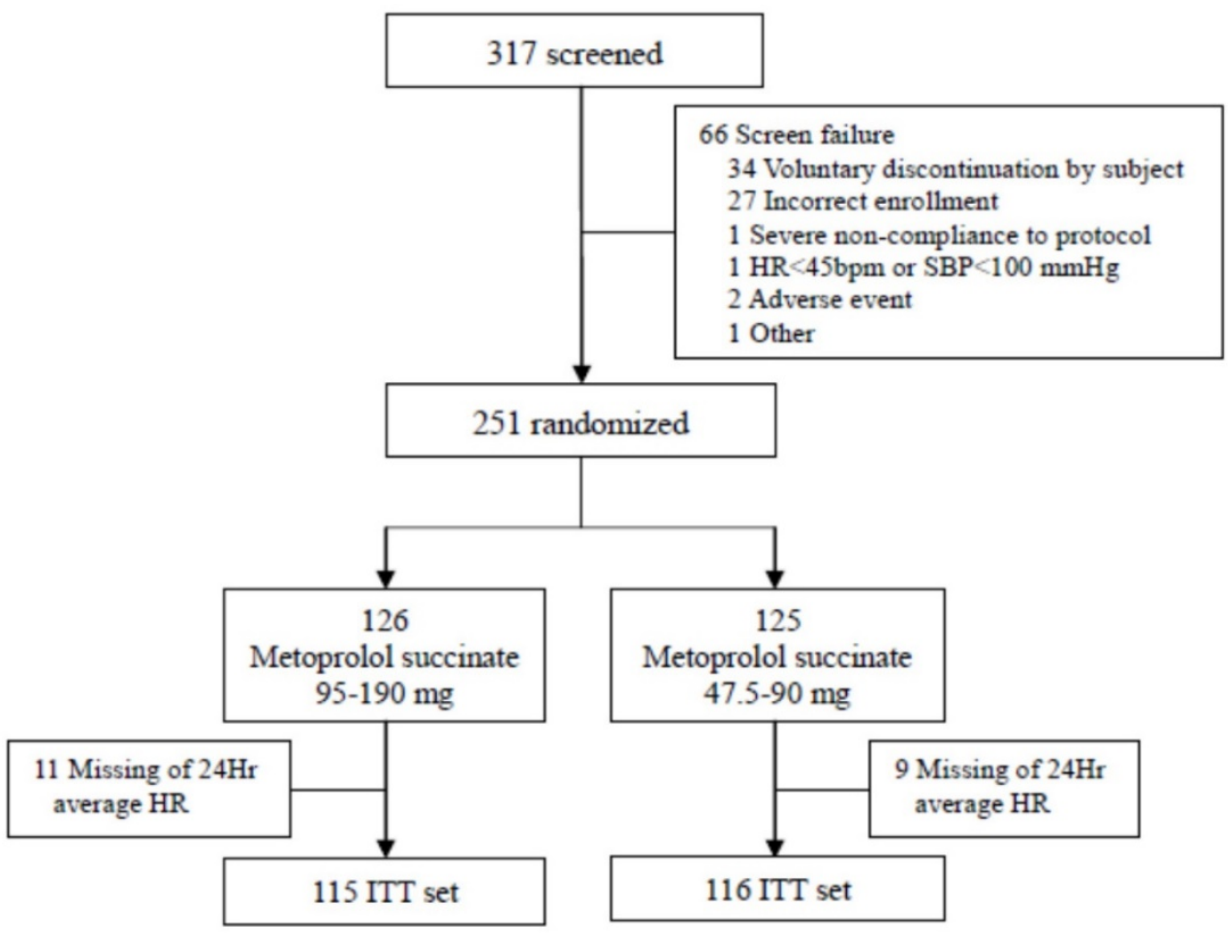

Figure 1. Flow chart illustrating the selection process 
Table 1. Characteristics of ITT patients in the two treatment groups

\begin{tabular}{|c|c|c|c|}
\hline $\begin{array}{l}\text { Parameter } \\
\text { Mean } \\
\text { (SD)/Number } \\
(\%)\end{array}$ & $\begin{array}{l}\text { 190-mg group } \\
(\mathrm{n}=115)\end{array}$ & $\begin{array}{l}\text { 95-mg group } \\
(\mathrm{n}=116)\end{array}$ & $\begin{array}{l}\text { Overall } \\
(n=231)\end{array}$ \\
\hline Age (years) & $59.2(9.25)$ & $59.3(7.81)$ & $59.2(8.53)$ \\
\hline Male & $81(70.4)$ & $74(63.8)$ & $155(67.1)$ \\
\hline Hypertension & $62(53.9 \%)$ & $55(47.4 \%)$ & $117(50.6 \%)$ \\
\hline Hyperlipidemia & $19(16.5 \%)$ & $16(13.8 \%)$ & $35(15.2 \%)$ \\
\hline Diabetes mellitus & $15(13.0 \%)$ & $16(13.8 \%)$ & $31(13.4 \%)$ \\
\hline $\begin{array}{l}\text { Myocardial } \\
\text { infarction }\end{array}$ & $5(4.3 \%)$ & $3(2.6 \%)$ & $8(3.5 \%)$ \\
\hline $\begin{array}{l}\text { Cerebral } \\
\text { infarction }\end{array}$ & $4(3.5 \%)$ & $6(5.2 \%)$ & $10(4.3 \%)$ \\
\hline $\begin{array}{l}\text { Systolic BP } \\
(\mathrm{mmHg})\end{array}$ & 132.3(15.39) & 132.6(15.76) & $132.4(15.54)$ \\
\hline $\begin{array}{l}\text { Diastolic BP } \\
(\mathrm{mmHg})\end{array}$ & 78.9(11.22) & $80.1(9.78)$ & 79.5(10.52) \\
\hline HR (Beats/min) & $71.0(6.63)$ & $71.8(6.84)$ & $71.4(6.73)$ \\
\hline BMI $\left(\mathrm{kg} / \mathrm{m}^{2}\right)$ & $25.70(3.363)$ & $25.64(3.169)$ & $25.67(3.260)$ \\
\hline
\end{tabular}

Table 2. Change in 24-hr average HR from baseline compared between treatment groups (ITT set)

\begin{tabular}{lllll}
\hline & $\begin{array}{l}\text { Metoprolol } \\
\text { succinate } \\
190 \mathrm{mg} \text { group * } \\
(\mathrm{n}=115)\end{array}$ & $\begin{array}{l}\text { Metoprolol } \\
\text { succinate } \\
95 \mathrm{mg} \text { group * } \\
(\mathrm{n}=116)\end{array}$ & $\begin{array}{l}\text { Group } \\
\text { difference }\end{array}$ & p-value \\
\hline $\begin{array}{l}2 \text { weeks' } \\
\text { treatment }\end{array}$ & & & & \\
$\begin{array}{l}\text { LS mean* (SE) } \\
\text { change }\end{array}$ & $-2.14(0.51)$ & $-0.49(0.44)$ & 1.64 & 0.0110 \\
& & & $(95 \% \mathrm{CI}: 0.38$, & \\
$\begin{array}{l}\text { 8 weeks' } \\
\text { treatment }\end{array}$ & & & $2.91)$ & \\
$\begin{array}{l}\text { LS mean" (SE) } \\
\text { change }\end{array}$ & $-2.99(0.62)$ & $-0.62(0.69)$ & 2.36 & 0.0077 \\
& & & $(95 \% \mathrm{CI}: 0.63$, & \\
& & & $4.09)$ & \\
\hline
\end{tabular}

* Adjusted change from baseline

\# Least squares' (LS) means. Group difference is $95 \mathrm{mg}$ group minus $190 \mathrm{mg}$ group.

Table 3. Proportion of patients with resting HR $\leq 60 \mathrm{bpm}$ during randomized treatment compared with baseline (ITT set)

\begin{tabular}{|c|c|c|c|c|}
\hline & $\begin{array}{l}\text { Metoprolol } \\
\text { succinate } \\
190 \text { mg group } \\
(\mathrm{n}=115)\end{array}$ & $\begin{array}{l}\text { Metoprolol } \\
\text { succinate } \\
95 \text { mg group } \\
(\mathrm{n}=116)\end{array}$ & Group difference & $\mathrm{p}$-value \\
\hline \multicolumn{5}{|l|}{ Baseline } \\
\hline Controlled * & $16(13.9 \%)$ & $27(23.3 \%)$ & & \\
\hline \multicolumn{5}{|l|}{$\begin{array}{l}2 \text { weeks' } \\
\text { treatment }\end{array}$} \\
\hline Controlled * & $28(24.3 \%)$ & $25(21.6 \%)$ & $\begin{array}{l}2.8 \% \\
\text { (95\% CI: }-8.04 \%, \\
13.64 \%)\end{array}$ & $>0.05$ \\
\hline p-value $\#$ & 0.0105 & 0.7055 & & \\
\hline \multicolumn{5}{|l|}{$\begin{array}{l}8 \text { weeks' } \\
\text { treatment }\end{array}$} \\
\hline Controlled * & $46(40.0 \%)$ & $28(24.1 \%)$ & $\begin{array}{l}15.9 \% \\
(95 \% \text { CI: } 4.00 \%, \\
27.73 \%)\end{array}$ & 0.0019 \\
\hline $\mathrm{p}$-value $\#$ & $<0.0001$ & 0.8415 & & \\
\hline
\end{tabular}

* Resting HR controlled to $\leq 60 \mathrm{bpm}$.

\#Compared with baseline

\section{Safety parameters}

During the treatment period, the percentage of patients who reported AEs in the 190-mg group $(16.1 \%)$ was slightly higher than that in the 95-mg group (12.2\%). Similarly, drug-related AEs were also marginally more common in the 190 -mg group $(9.8 \%)$ than in the $95-\mathrm{mg}$ group $(7.9 \%)$. The percentages of patients with serious AEs were $0.7 \%$ and $2.7 \%$ in the 95-mg and 190-mg groups, respectively. No death occurred in the study.

The percentages of patients who discontinued the drug therapy because of an AE were similar in both groups (95-mg group, 4.3\%; 190-mg group, $4.5 \%)$. Only six patients $(2.2 \%)$ discontinued the treatment because of hypotension (SBP $<100 \mathrm{mmHg}$ ); four of them were from the 95-mg group while two were from the 190-mg group. Two patients (both from the 95-mg group) withdrew from the study because of bradycardia; one developed sinus bradycardia and one had an HR of $<45 \mathrm{bpm}$.

There was no significant difference between the two groups in the changes in fasting plasma glucose, total cholesterol, and triglyceride levels from baseline (Table 4).

Table 4. Changes in blood chemistry from baseline after 8 weeks' treatment

\begin{tabular}{|c|c|c|c|c|c|}
\hline & & $\begin{array}{l}\text { Metoprolol succinate } \\
190 \text { mg group } \\
(\mathrm{n}=115)\end{array}$ & $\begin{array}{l}\text { Metoprolol } \\
\text { succinate } \\
95 \text { mg group } \\
(\mathrm{n}=116)\end{array}$ & $\begin{array}{l}\text { Group } \\
\text { difference }\end{array}$ & p-value ${ }^{*}$ \\
\hline \multicolumn{6}{|c|}{ Change from baseline (mmol/L) } \\
\hline FPG & $\begin{array}{l}\text { mean } \\
95 \% \mathrm{CI}\end{array}$ & $\begin{array}{l}0.38 \\
0.11,0.66\end{array}$ & $\begin{array}{l}0.25 \\
-0.03,0.53\end{array}$ & $\begin{array}{l}0.14 \\
-0.23,0.50\end{array}$ & 0.4672 \\
\hline \multirow[t]{2}{*}{ TC } & mean & 0.58 & -0.05 & -0.63 & 0.1478 \\
\hline & $95 \% \mathrm{CI}$ & $-0.10,1.27$ & $-0.71,0.61$ & $-1.49,0.22$ & \\
\hline TG & $\begin{array}{l}\text { mean } \\
95 \% \mathrm{CI}\end{array}$ & $\begin{array}{l}0.09 \\
-0.08,0.27\end{array}$ & $\begin{array}{l}0.13 \\
-0.04,0.30\end{array}$ & $\begin{array}{l}0.04 \\
-0.21,0.28\end{array}$ & 0.7719 \\
\hline
\end{tabular}

*p-value for group difference by mixed model repeated measures analysis of safety population.

\section{Discussion}

The association between increased HR and overall cardiac mortality or other adverse outcomes in CHD patients has been well established by previous studies [4, 11-13]. A sub-analysis of the BEAUTIFUL study [14] showed that HR reduction by medication is related to better clinical outcomes in selected patients with CHD. Furthermore, a meta-regression analysis [15] demonstrated a statistically significant relationship between resting $\mathrm{HR}$ reduction by $\beta$-blockers and clinical benefits, including reductions in cardiac death $(\mathrm{p}<0.001)$, all-cause death $(\mathrm{p}=$ $0.008)$, sudden death $(\mathrm{p}=0.015)$, and recurrent non-fatal myocardial infarction $(p=0.024)$. Each 10 
bpm reduction in $\mathrm{HR}$ is estimated to reduce the relative risk of cardiac death by $30 \%$.

Researchers have long discussed the ideal range for target HR. The Framingham Heart Study showed that CHD mortality rates rose considerably with increasing $\mathrm{HR}$, with the lowest mortality rate observed in patients with an HR $<65$ bpm[16]. Moreover, according to an analysis of the Treating to New Targets (TNT) study based on a Cox proportional hazard model, a nadir HR of $52.4 \mathrm{bpm}$ was associated with the lowest rate of AEs [17]. Based on established clinical evidence, the guidelines for the treatment of stable angina recommend a target resting $\mathrm{HR}$ of 55-60 bpm [4, 5]. Hence, we set the target HR at $60 \mathrm{bpm}$ in the present study.

The effectiveness of $\beta$-blockers in controlling HR is well established. According to one report, atenolol, bisoprolol, and metoprolol were more effective than other $\beta$-blockers in managing resting $\mathrm{HR}$ in $\mathrm{CHD}$ patients [9]. Previous studies of multiple patient groups have demonstrated that changes in both 24-h average $H R$ and resting HR were related to the dosage of $\beta$-blocker administered [18, 19]. In a study involving Chinese $\mathrm{CHD}$ patients who were $\beta$-blocker-naive, $42.5 \%$ and $79.4 \%$ of the patients achieved a HR of less than $70 \mathrm{bpm}$ after one and two months of metoprolol succinate treatment, respectively [18]. Baseline HR and metoprolol succinate dosage were independent predictors of the resting HR two months after $\beta$-blocker therapy. The present study revealed that $190 \mathrm{mg}$ metoprolol succinate has a better effect in reducing HR than a 95 $\mathrm{mg}$ dose, as seen by both the 24-h average HR and the percentage of patients with resting $\mathrm{HR}<60 \mathrm{bpm}$ after eight weeks of treatment. In general, the higher dose of the drug was well tolerated by patients. Although the data exhibited the same trend seen in earlier studies, the decrease in HR induced by the drug was less than previously reported values.

The change in HR following metoprolol succinate treatment observed in this study was relatively small, especially in the 95-mg group. There may be several reasons why the drug was less effective in these patients. Firstly, to simulate the common clinical population of patients who are on low-dose $\beta$-blocker medication and have an elevated $\mathrm{HR}$, only patients who were on $\beta$-blocker therapy at a dose equivalent to $23.75-47.5 \mathrm{mg}$ metoprolol succinate with $\mathrm{HR} \geq 65 \mathrm{bpm}$ were included in the present study. For these patients, who can tolerate a low dose of metoprolol succinate well, a higher dose of the drug may be needed to better block the $\beta$-receptors. It has been shown that the cardiac autonomic nervous system is impaired in CHD patients who have increased sympathetic nerve excitability [20].
Secondly, a higher dose of metoprolol succinate may result in a higher threshold for angina, allowing for increased physical activity and thus a higher daytime HR, which will increase the 24-h average HR. Moreover, as suggested by the MERIT-HF study [21], the dose-response relationship of metoprolol succinate may exhibit an exponential correlation, which partly explains the lack of efficacy of the $95 \mathrm{mg}$ dose.

The possible difference in $\beta$-blocker tolerability between patients from China and Western countries is one of the reasons why physicians are reluctant to prescribe a high dose of these drugs in China. In the present study, metoprolol succinate was well tolerated by the majority of patients, without extreme HR reduction. Furthermore, patients treated with the higher dose of metoprolol succinate did not report additional AEs. The incidence of AEs during the study was comparable to that at 12 weeks of treatment with 5-7.5 mg ivabradine b.i.d or 12.5-25 mg atenolol b.i.d in Chinese patients with stable angina, where the reported incidence of all AEs was 27.4\% [22], further supporting the proposition that $190 \mathrm{mg}$ metoprolol succinate can be safely prescribed for Chinese patients.

There are several limitations to our investigation. Although this study was innovative in using the 24-h average $H R$ as the primary outcome parameter, unlike previous studies it was not designed to obtain detailed HR information during the day. Additionally, $\beta$-blockers have different effects on resting and exercise HR; thus, the efficacy and tolerability of different drug doses would be better measured with additional parameters, such as the lowest and highest HR during the 24-h period. Furthermore, a group of patients who can tolerate only a low dose of $\beta$-blockers was not included in this trial. There may be differences in the effect of $\beta$-blockers on patient outcomes between those who are sensitive to these drugs and those who are not, independently of HR control. Hence, further studies are needed to address these questions.

\section{Conclusion}

A metoprolol succinate dose of $190 \mathrm{mg}$ was superior to a $95 \mathrm{mg}$ dose in controlling the HR of stable angina patients with elevated HR who were on a low-dose $\beta$-blocker therapy; the treatment was well tolerated by these patients. Only the administration of $190 \mathrm{mg}$ metoprolol succinate achieved the treatment goal of controlling HR to $\leq 60 \mathrm{bpm}$ in this patient population. Close follow-up and careful dose titration will be needed to achieve the goal for HR control in these patients. 


\section{Abbreviations}

HR: heart rate; bpm: beats per minute; CHD: coronary heart disease; SBP: systolic blood pressure; LVEF: left ventricular ejection fraction; AE: adverse event; ITT: intent-to-treat; OR: odds ratios; CI: confidence interval

\section{Acknowledgement}

This study was sponsored by AstraZeneca (Study code: D4022L00008; ClinicalTrials.gov identifier: NCT01213173).

\section{Competing Interests}

The study is supported by AstraZeneca and there is no other competing interest.

\section{References}

1. Kannel WB, Kannel C, Paffenbarger RS Jr, et al. Heart rate and cardiovascular mortality: the Framingham Study. Am Heart J. 1987; 113: 1489-94.

2. Dyer AR, Persky V, Stamler J, et al. Heart rate as a prognostic factor for coronary heart disease and mortality: findings in three Chicago epidemiologic studies. Am J Epidemiol.1980; 112:736-49.

3. Paul L, Hastie CE, Li WS, et al. Resting heart rate pattern during follow-up and mortality in hypertensive patients. Hypertension. 2010; 55: 567-74.

4. Fox K, Borer JS, Camm AJ, et al; Heart Rate Working Group. Resting heart rate in cardiovascular disease. J Am Coll Cardiol. 2007; 50: 823-30.

5. Chinese Society of Cardiology. [Guideline for diagnosis and treatment of patients with chronic stable angina]. Zhonghua Xin Xue Guan Bing Za Zhi. 2007; 35: 195-206

6. Jneid H, Anderson JL, Wright RS, et al; American Heart Association Task Force on Practice Guidelines. 2012 ACCF/AHA focused update of the guideline for the management of patients with unstable angina/Non-ST-elevation myocardial infarction (updating the 2007 guideline and replacing the 2011 focused update): a report of the American College of Cardiology Foundation/American Heart Association Task Force on practice guidelines. Circulation. 2012; 126: 875-910.

7. Steg PG, Ferrari R, Ford I, et al; CLARIFY Investigators. Heart rate and use of beta-blockers in stable outpatients with coronary artery disease. PLoS One. 2012; 7: e36284.

8. Jiang J, Wang X, Jia J, et al; Chinese Chronic Stable Angina Medical Therapy Adherence Survey Investigators. [Current status and influence factors of beta blocker prescription in Chinese patients with stable angina pectoris]. Zhonghua Xin Xue Guan Bing Za Zhi. 2015; 43: 227-33.

9. Cordero A, Bertomeu-González V, Mazón P, et al. Differential effect of $\beta$-blockers for heart rate control in coronary artery disease. Clin Cardiol. 2011; 34: 748-54.

10. Yusuf S, Islam S, Chow CK, et al; Prospective Urban Rural Epidemiology (PURE) Study Investigators. Use of secondary prevention drugs for cardiovascular disease in the community in high-income, middle-income, and low-income countries (the PURE Study): a prospective epidemiological survey. Lancet. 2011; 378: 1231-43.

11. Diaz A, Bourassa MG, Guertin MC, et al. Long-term prognostic value of resting heart rate in patients with suspected or proven coronary artery disease. Eur Heart J. 2005; 26: 967-74.

12. Kolloch R, Legler UF, Champion A, et al. Impact of resting heart rate on outcomes in hypertensive patients with coronary artery disease: findings from the INternational VErapamil-SR/trandolapril STudy (INVEST). Eur Heart J. 2008; 29: 1327-34.

13. Antoni ML, Boden H, Delgado V, et al. Relationship between discharge heart rate and mortality in patients after acute myocardial infarction treated with primary percutaneous coronary intervention. Eur Heart J. 2012; 33: 96-102.

14. Fox K, Ford I, Steg PG, et al; BEAUTIFUL Investigators. Relationship between ivabradine treatment and cardiovascular outcomes in patients with stable coronary artery disease and left ventricular systolic dysfunction with limiting angina: a subgroup analysis of the randomized, controlled BEAUTIFUL trial. Eur Heart J. 2009; 30: 2337-45.

15. Cucherat M. Quantitative relationship between resting HR reduction and magnitude of clinical benefits in post-myocardial infarction: a meta-regression of randomized clinical trials. Eur Heart J. 2007; 28: 3012-9.

16. Gillman MW, Kannel WB, Belanger A, et al. Influence of heart rate on mortality among persons with hypertension: the Framingham Study. Am Heart J. 1993; 125: 1148-54

17. Bangalore S, Wun CC, Demicco D, et al. HR in patients with coronary artery disease - the lower the better? An analysis from the Treating to New Targets (TNT) trial. Eur Heart J. 2011; 32 (Supplement): 339.
18. Zhao $\mathrm{YX}, \mathrm{Li} \mathrm{YP}, \mathrm{Gao} F$, et al. Heart rate distribution and predictors of resting heart rate after initiation of beta-blocker treatment in patients with coronary artery disease: REsults of Sympathetic Evaluation And Research of China (RESEARCH) study. Chin Med J (Engl). 2013; 126: 3460-3.

19. Lücker $P$, Moore G, Wieselgren I, et al. Pharmacokinetic and pharmacodynamic comparison of metoprolol CR/ZOK once daily with conventional tablets once daily and in divided doses. J Clin Pharmacol. 1990; 30: S17-27.

20. Huikuri HV, Niemelä MJ, Ojala $S$, et al. Circadian rhythms of frequency domain measures of heart rate variability in healthy subjects and patients with coronary artery disease. Effects of arousal and upright posture. Circulation. 1994; 90: 121-6.

21. [No authors listed]. Effect of metoprolol $\mathrm{CR} / \mathrm{XL}$ in chronic heart failure: Metoprolol CR/XL Randomised Intervention Trial in Congestive Heart Failure (MERIT-HF). Lancet. 1999; 353: 2001-7.

22. Li Y, Jing L, Li Y, et al. The efficacy and safety of ivabradine hydrochloride versus atenolol in Chinese patients with chronic stable angina pectoris. Pharmacoepidemiol Drug Saf. 2014; 23: 1183-91. 